\title{
Traceability of near-field goniophotometers to the SI units
}

\begin{abstract}
Goniophotometry is one of the basic photometric measurements in lighting engineering. Aim is to measure spatial characteristics of luminous parts of the luminaires and light sources represented by luminous intensity distribution curve which is needed for lighting computation at level of the preparation of lighting design. Near-field goniophotometry is still a forthcoming technology widely used in photometric laboratories all over the world. Due to compact design of these systems the laboratory space can be saved and they can be installed in a room of usual dimensions because they do not obey the inverse square law from point of view of the whole dimension of the luminaire. The principle of these goniophotometers of the luminance distribution is measurement of luminous part of the luminaires and light sources. By integration over solid angle from this fundamental photometric quantity luminous intensity in particular direction in the space represented by two angles depending on measurement planes is derived. Although theoretical principle and physical model is well-known and defined, in practical realisation of this system some problems occur. One of the problems is traceability to SI units. This fact disqualifies near-field goniophotometer in standards relating to goniophotometry. The methods to prove that near-field goniophotometer works are mostly based on computer simulations compared with practical measurements. But in the practice, appropriate calibration method with traceability to the SI units is still not available, unlike it is clearly used for farfield goniophotometers. The paper describes possibility of the calibration of near-field goniophotometers to SI units by standards which should provide fully traceable calibration to the base. Also method of validation of near-field goniophotometric systems is still opened question for future work. At the present, further works continue on the method of validation in the framework of that CIE Division 2 but this topic is out of scope of this paper.
\end{abstract}

Keywords: Goniophotometry, Near-field goniophotometer, LIDC.

\section{Introduction}

At the present two important standards about LED luminaires are under preparation beside the already issued and approved document LM-79. In these documents broader scope is dedicated to goniophotometry of LED sources respective LED luminaires. In laboratories there are existing goniophotometers of various types according to CIE 121:1996 The Photometry and Goniophotometry of Luminaires. Very often discussed topic is the use of a goniophotometer of type A i.e. with rotating luminaire for LED products. This type of goniophotometer is widely used in many photometric laboratories for its favourable price and moderate space requirements.During the measurement the work position of the luminaire changes with every rotation of the goniophotometer. There exists doubt how large the error is, compared to sytems, where the luminaire is not changing in Earth's gravitational field. Auxiliary photometer has to be used for possible corrections at the measurement. In the papers is very hard to find something about position of this photometer. Therefore decision was on laboratory agreement how to perform measurement with it. Three LED luminaires were chosen as comparison batch each with different LIDC to show also the influence of different types of luminaires. We show also how big the influence is when measuring a luminaire in the so-called false $\mathrm{C}$ planes where the inverted luminaire's luminous part is twisted by $90^{\circ}$ and so it is aimed towards photometer head. After performing the comparison between the laboratories results were compared to catalogue values of luminaires which were derived from measurements done by using C-plane goniophotometers where the position of the luminaire is kept unchnged in the Earth's gravitational field. The whole comparison measurement procedure, described below, was properly arranged and discussed at the laboratories before starting any measurements. Additionally, also the electrical quantities of luminaires were measured at each laboratory.

\section{Nearfield goniophotometry}

Goniofotometer with near-field measured the brightness distribution of the light source or luminaire radiating from all angles using a device for measuring the brightness. Utter determination of the distribution of brightness $L\left(x_{\mathrm{S}}, y_{\mathrm{S}}, z_{\mathrm{S}}, \vartheta\right.$ $s, \varphi s$ ) of the lamp or luminaire comprising measuring luminance in all directions in which light is emitted. The brightness distribution is characteristic of the light source is defined in several basic $\mathrm{d} A_{\mathrm{S}}\left(x_{\mathrm{S}}, y_{\mathrm{S}}, z_{\mathrm{S}}\right)$ Light surface. It describes the directional dependence of the variation of brightness elementary $\mathrm{d} A_{\mathrm{S}}\left(x_{\mathrm{S}}, y_{\mathrm{S}}, z_{\mathrm{S}}\right)$ on the surface of the object:

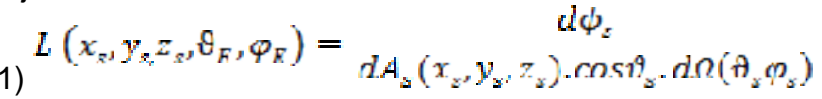
where d $\phi s$ is part of luminous flux of spatial angle $\left(\vartheta_{S}, \varphi_{S}\right)$ and $\vartheta_{S}$ is the angle between the elemental areas of $d A s$ and azimuth element.

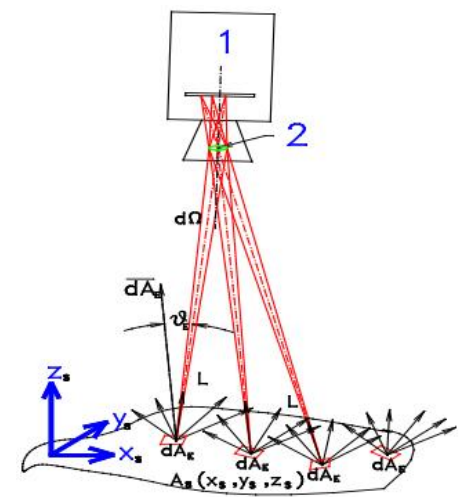

Fig.1. brightness distribution on the illuminated area

Goniofotometer with near-field uses a special camera (for measuring brightness) to register the distribution of brightness light source or luminaire in all directions in which light is emitted. The measurement is performed by moving the measuring camera, which is arranged on the rotating arm goniophotometer. This arm and thus the camera rotates around an imaginary spherical surface light source or luminaire. 


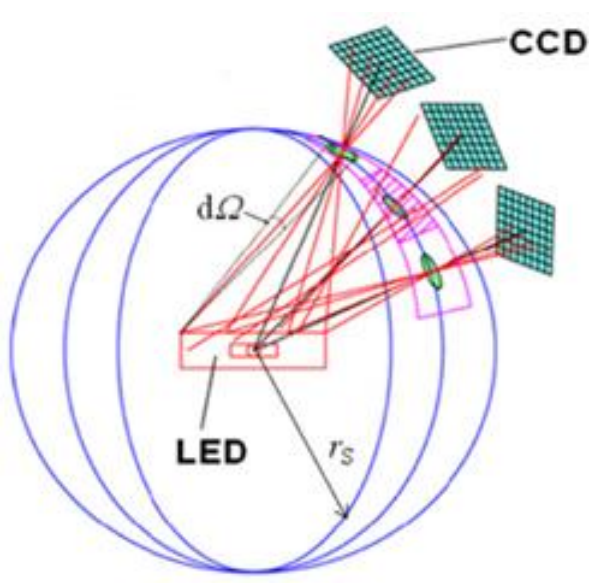

Fig.2. Principles of measurement of nearfield goniophotometer

Luminous flux is measured by formula:

(2) $\quad \phi=\int_{A} \int_{\Omega} L(x, y, z, \vartheta, \varphi) \cdot d A \cdot \cos \vartheta \cdot d \Omega$

It will be like a sum of all radiated date. After,

(3) $\quad \phi=\sum_{x_{s} y_{s} z_{s}} \sum_{\vartheta_{s} \varphi_{s}} \Delta \phi\left(x_{s} y_{s} z_{s} \vartheta_{s} \varphi_{s}\right.$

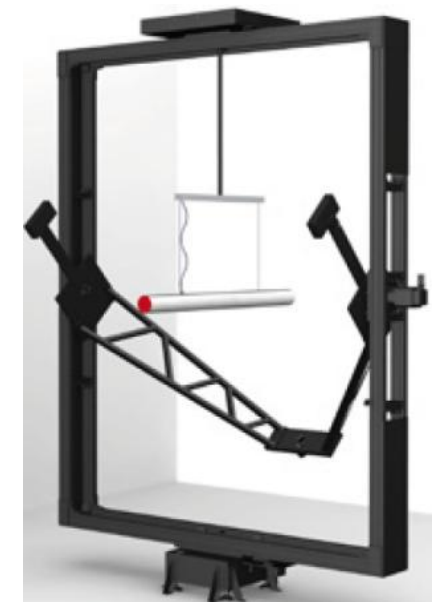

Fig.3. Nearfield goniophotometer Rigo 801

\section{Standards of luminance for calibrations photometric scale of luminance meters}

The first method is implemented by optical rail system and integrating sphere. Components, apertures and luxmeter are placed on rail system. Circular apertures were made by precision laser-cut technology with accuracy $0,1 \mathrm{~mm}$.

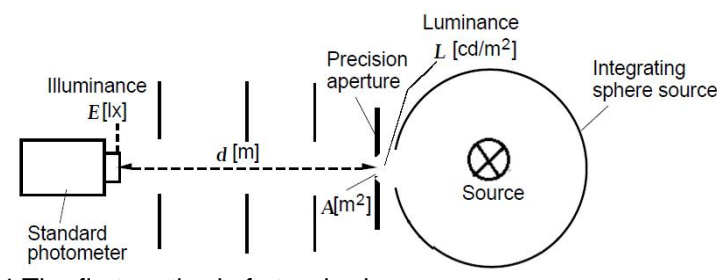

Fig.4 The first method of standard

The average luminance $L(\mathrm{~cd} / \mathrm{m} 2)$ over the aperture plane is determined from the illuminance $E(\mathrm{~lx})$, the distance, $d(\mathrm{~m})$, and the aperture area, $A(\mathrm{~m} 2)$, as given by where $k$ is a geometrical correction factor determined by the radius, $r a$, of the aperture, the radius, $r d$, of the detector sensitive area, and the distance, $d$, as given by

(5) $k=1+\left(\frac{r_{a}}{d}\right)^{2}+\left(\frac{r_{d}}{d}\right)^{2}$

The second method is implemented by photometric bench and opal glass with aperture.

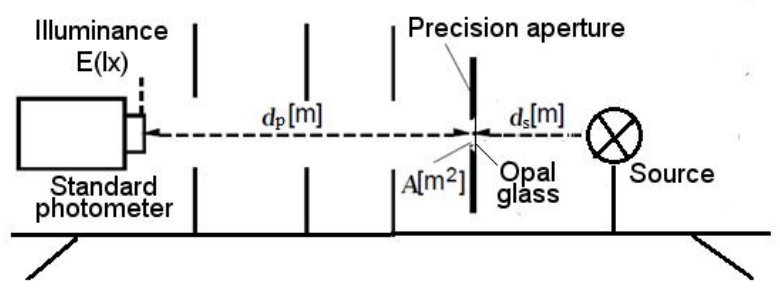

Fig.5 The second method of standard

The average luminance $L\left(\mathrm{~cd} / \mathrm{m}^{2}\right)$ is determined from the illuminance $\mathrm{E}(\mathrm{Ix})$ and luminance coefficient $\mathrm{q}\left(\mathrm{sr}^{-1}\right)$, as given by

(6)

$$
L=q E
$$

Luminance coefficient calculate:

$$
\mathrm{q}=\frac{k d_{p}^{3} E_{1}}{A E_{0} \Omega_{\mathbf{a}}}
$$

where $A$ is a content of area illumination part of opal glass, $k$ is a geometrical correction factor determined by the radius, ra, of the aperture, the radius, $r d$, of the detector sensitive area, the distance between opal glass and standard photometer, $d_{p}$ and the distance between opal glass and source, $d_{s}$ as given by

$$
k=1+\left(\frac{r_{a}}{d_{p}}\right)^{2}+\left(\frac{r_{d}}{d_{s}}\right)^{2}
$$

Illuminance $E$ can be measured by placing a standard photometer on the reference plane of the opal glass. Illuminance $E$ can also be determined by using a luminous intensity standard lamp applying the inverse square law. In this case the distance should be measured from the reference plane of the opal glass.

Measured and calculated values for standard implemented by integrating sphere

Table.1 Measured values
\begin{tabular}{|l|r|r|l|l|l|r|r|}
\hline & $\mathrm{E}(\mathrm{Ix})$ & $\mathrm{Ev}(\mathrm{Ix})$ & $\mathrm{d}$ & ra & rd & $\begin{array}{l}\text { measured } \\
(\mathrm{LMT}) \mathrm{cd} / \mathrm{m}^{2}\end{array}$ & $\begin{array}{l}\text { measured } \\
(\mathrm{M}) \mathrm{cd} / \mathrm{m}^{2}\end{array}$ \\
\hline 60W & 1,46 & 1,31 & 0,82 & 0,02 & 0,004 & 680 & 711 \\
\hline 200W & 4,66 & 4,2 & 0,87 & 0,02 & 0,004 & 2530 & 2565 \\
\hline
\end{tabular}

Table.2 Calculated values

\begin{tabular}{|l|l|l|r|r|r|}
\hline & $\mathrm{A}\left(\mathrm{m}^{2}\right)$ & $\mathrm{k}$ & $\mathrm{L}\left(\mathrm{cd} / \mathrm{m}^{2}\right)$ & offset (LMT) \% & offset (M) \% \\
\hline 60W & 0,001256 & 1,00062 & 695,28 & 2,2 & 2,26 \\
\hline 200W & 0,001256 & 1,00054 & 2545,34 & 0,6 & 0,77 \\
\hline
\end{tabular}

$$
L=k E d^{2} / A
$$


Measured and calculated values for standard implemented by photometric bench

Table.3 Measured values

\begin{tabular}{|c|c|c|c|c|c|c|}
\hline $200 W$ & $\mathrm{ds}(\mathrm{m})$ & $\mathrm{dp}(\mathrm{m})$ & \multicolumn{2}{|c|}{$\mathrm{ra}(\mathrm{m})$} & $\mathrm{rd}(\mathrm{m})$ & E1(Ix) \\
\hline $1 . \mathrm{m}$ & 0,3 & 0,65 & \multicolumn{2}{|c|}{0,04} & 0,004 & 2,18 \\
\hline $2 . \mathrm{m}$ & 0,47 & 0,34 & \multicolumn{2}{|c|}{0,04} & 0,004 & 3,1 \\
\hline $200 W$ & E0(Ix) & \multicolumn{2}{|c|}{$\begin{array}{l}\text { measured } \\
(\mathrm{LMT}) \\
\mathrm{cd} / \mathrm{m}^{2}\end{array}$} & \multicolumn{2}{|c|}{$\begin{array}{l}\text { measured } \\
\text { (M) } \mathrm{cd} / \mathrm{m}^{2}\end{array}$} & \\
\hline $1 . \mathrm{m}$ & 1669,6 & 173 & & & 171 & \\
\hline 2. $\mathrm{m}$ & 685,2 & 68,5 & & & 69,4 & \\
\hline
\end{tabular}

Tab.4 Calculated values

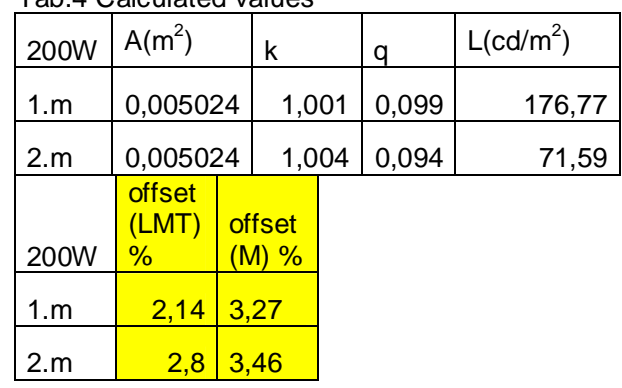

The Measurement uncertainty

The Measurement uncertainty was measured by derivation of formuls

$\mathrm{L}=\mathrm{k} . \mathrm{E} . \mathrm{d}^{2} / \mathrm{A}$ for standard implemented by integrating sphere and $L V=q^{*} E_{0}$ for standard implemented by photometric bench.

Standard implemented by integrating sphere:

Tab.5 The measurement uncertainty

\begin{tabular}{|l|r|r|r|r|r|}
\hline & \multicolumn{1}{|c|}{$100 \mathrm{~W}$} & \multicolumn{1}{l|}{$60 \mathrm{~W}$} & \multicolumn{1}{l|}{$200 \mathrm{~W}$} & \multicolumn{1}{l|}{$300 \mathrm{~W}$} & \multicolumn{1}{l|}{$500 \mathrm{~W}$} \\
\hline $\mathrm{u}_{\text {total }}\left(\mathrm{cd} / \mathrm{m}^{2}\right)$ & 45,94 & 30,2 & 110,17 & 178,2 & 318,21 \\
\hline $\mathrm{U}_{(\mathrm{k}=2)}\left(\mathrm{cd} / \mathrm{m}^{2}\right)$ & 91,87 & 60,4 & 220,34 & 356,4 & 636,41 \\
\hline
\end{tabular}

Standard implemented by photometric bench:

Tab.6 The measurement uncertainty

\begin{tabular}{|l|r|r|l|}
\hline $200 \mathrm{~W}$ & 1.measurement & \multicolumn{1}{l|}{ 2.m } & \multicolumn{1}{l|}{ 3.m } \\
\hline $\mathrm{U}_{\text {total }}\left(\mathrm{cd} / \mathrm{m}^{2}\right)$ & 7,83 & 7,89 & 3,11 \\
\hline $\mathrm{U}_{(\mathrm{k}=2)}\left(\mathrm{cd} / \mathrm{m}^{2}\right)$ & 15,66 & 15,78 & 6,22 \\
\hline
\end{tabular}

\section{Comparison between near field and far field}

One of the possibility how to prove or validate ability of near-field goniophotometric system for measurement of LIDC according to mentioned standards is to show reasonable results between far-field and near-field type of goniophotometer used for this purpose. Comparison of chosen validated far-field goniophotometers with near-field goniophotometers between two photometric laboratories results of comparison of different types of near-field goniophotometers with respect to the LIDC measurement measurement of LIDCs of various luminaires with different optics and design where problems of measurement by near-field goniphotometer occur.

In the picture 6 we can see comparison between far field and near field goniophotometry. In the left side of picture 6 are measurements by far field and on the right side are measurements by near field.
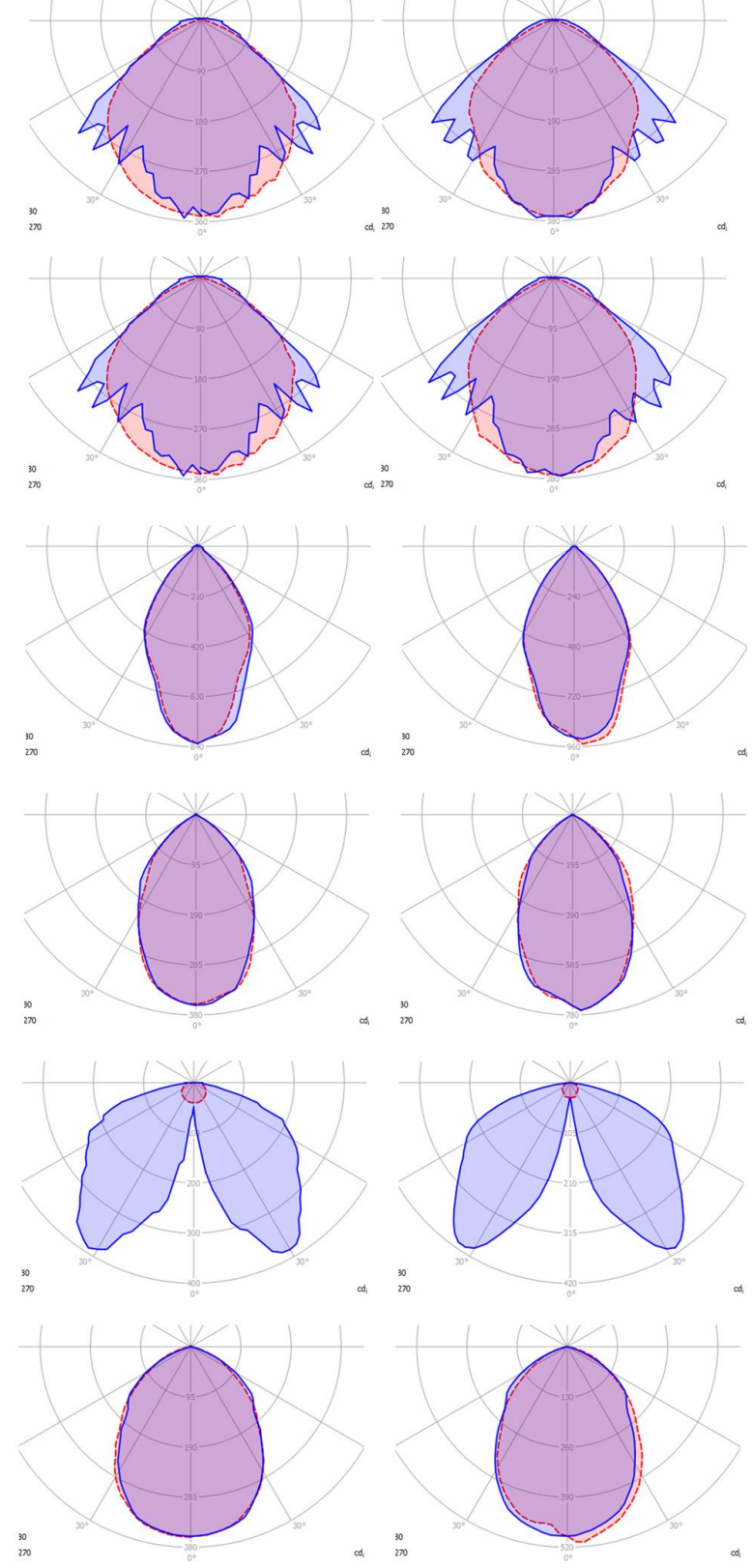

\section{Conclusions}

In the paper was presented traceability of near field goniophotometers to SI units. It means we used standards for calibration of luminance and too for luminous flux. Now is ensured traceability to SI units. The measurement was performed by farfield double-goniophotometric system and farfield rotational luminaire goniophotometric system. The near-field goniophotometer with ILMD and photometer head was used for measurement. The results in the comparison shown some differencies in the LIDC shape for some luminaires with stable luminaire. Based on the measurements can be assesed appropriate validation guidance for the near-field goniophotometers. 


\section{Acknowledgments}

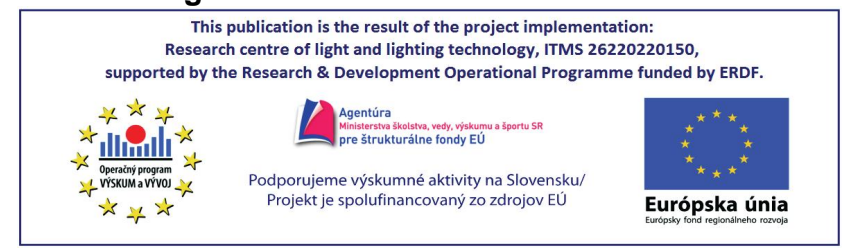

\section{REFERENCES}

[1] GRUM F., BECHERER R. J., 1979 „Optical radiation measurements vol. 1: Radiometry," Academic Press: 1979

[2] OSA/AIP, Handbook of Applied Optics, Edited by Casimer DeCusatis, Chapter 1 (1997)

[3] CIE 1996. CIE 121:1996. The Photometry and Goniophotometry of Luminaires. Vienna: CIE.

[4] CIE 2012. CIE DS 023/E:2012. Characterization of the Performance of Illuminance Meters and Luminance Meters. Vienna: CIE.

[5]BIPM 2008. JCGM 100:2008. Guide to the expression of uncertainty in measurement, Paris: BIPM CIE 2010. CIE 191:2010 Recommended System for Mesopic Photometry Based on Visual Performance. Vienna: CIE

Authors: Mgr. Roman Dubnička, Slovenská technická univerzita, Fakulta elektrotechniky a informatiky, Ilkovičova 3, Slovak republic, e-mail: roman.dubnicka@stuba.sk 